NBER WORKING PAPER SERIES

\title{
EFFICIENT RULES FOR MONETARY POLICY
}

Laurence Ball

Working Paper 5952

\author{
NATIONAL BUREAU OF ECONOMIC RESEARCH \\ 1050 Massachusetts Avenue \\ Cambridge, MA 02138 \\ March 1997
}

I am grateful for comments and assistance from Bob Buckle, David Mayes, David Romer, numerous seminar participants, and especially Hailong Qian. Financial support was provided by the Reserve Banks of Australia and New Zealand. This paper is part of NBER's research programs in Economic Fluctuations and Growth and Monetary Economics. Any opinions expressed are those of the author and not those of the National Bureau of Economic Research.

(C) 1997 by Laurence Ball. All rights reserved. Short sections of text, not to exceed two paragraphs, may be quoted without explicit permission provided that full credit, including $\mathbb{C}$ notice, is given to the source. 
Efficient Rules for Monetary Policy

Laurence Ball

NBER Working Paper No. 5952

March 1997

JEL No. E52

Economic Fluctuations and Growth

and Monetary Economics

\begin{abstract}
This paper defines an efficient rule for monetary policy as one that minimizes a weighted sum of output variance and inflation variance. It derives several results about the efficiency of alternative rules in a simple macroeconomic model. First, efficient rules can be expressed as "Taylor rules" in which interest rates respond to output and inflation. But the coefficients in efficient Taylor rules differ from the coefficients that fit actual policy in the United States. Second, inflation targets are efficient. Indeed, the set of efficient rules is equivalent to the set of inflation-target policies with different speeds of adjustment. Finally, nominal-income targets are not merely inefficient, but disastrous: they imply that output and inflation have infinite variances.
\end{abstract}

Laurence Ball

Department of Economics

Johns Hopkins University

Baltimore, MD 21218

and NBER 


\section{INTRODUCTION}

How can monetary policymakers stabilize output and inflation? There is growing sentiment that policy should be guided by some fairly simple rule. But there is controversy about what rule would be best. Popular rules include inflation targets, nominal-income targets, and "Taylor rules" in which interest rates respond to output and inflation. This paper asks which policy rule is optimal in a simple macroeconomic model.

The model is similar to ones in Taylor (1994), Hall and Mankiw (1994), and Svensson (1996a). It contains two equations. The first is a dynamic IS equation: output depends on lagged output and a lagged interest rate. The second is an accelerationist Phillips curve: the change in inflation depends on lagged output. The model departs from much work on policy rules by emphasizing lags in the effects of policy and inertia in inflation. It is also simpler than the medium- and large-scale models used in recent research.'

As emphasized by Taylor (1994), the choice of a policy rule determines the variances of output and inflation. The "optimal" rule is naturally defined as the one that minimizes a weighted sum of these variances, with the weights determined by policymakers' tastes. An "efficient" rule is one that is optimal for some choice of weights. Equivalently, an efficient rule puts the economy on the inflation variance / output variance frontier. This paper asks which policy rules are efficient.

There are three sets of results. The first concerns the properties of Taylor rules. These rules are of interest because, as shown by Taylor (1993a) and others, they describe actual policy over

${ }^{1}$ The recent literature on policy rules is large. Some examples are McCallum (1993), Henderson and McKibbin (1993), Taylor (1993b), Cukierman (1995), Frankel and Chinn (1995), Hansen (1996), Matheny (1996), and the papers in Bryant et al. (1993). This work builds on earlier papers such as Bean (1983), Taylor (1985), and West (1986). 
the last decade in several countries, including the United States. In my model, any efficient policy can be expressed as a Taylor rule. However, not all Taylor rules are efficient. Efficiency implies restrictions on the Taylor-rule coefficients on output and inflation, which I derive.

This result yields an application of the model: we can ask whether policy in various countries is efficient. The countries that follow Taylor rules have coefficients of roughly one half on both output and inflation: the real interest rate is adjusted half a point for each percentage change in these variables. For plausible parameter values, my model suggests that the coefficient on output is too low. That is, policy does not lean hard enough against output fluctuations. A larger output coefficient would reduce the variances of both output and inflation by dampening inflationary booms and disinflationary recessions.

The second set of results concerns inflation targets. A number of countries have adopted inflation targets in the 1990s, including New Zealand, Canada, and Sweden. In analyzing these policies, I distinguish between a narrow and a broad definition of inflation targeting. Under the narrow definition, policy tries to hit a fixed inflation target as closely as possible. When shocks push inflation away from the target, policy brings it back as quickly as possible. Under the broad definition, policy moves inflation toward the target, but not necessarily at maximum speed: there can be gradual adjustment after a shock. Such a policy appears closer than the narrowly-defined policy to actual practice in some countries.

My model yields favorable results about inflation targets. Both kinds of targets are efficient. Not surprisingly, narrowly-defined targets are optimal only for extreme policy tastes: policymakers must put no weight on output variance. However, a broadly-defined inflation target is optimal for any tastes. As one varies the weights on output and inflation, the optimal policies trace out inflation targets with adjustment speeds from zero to the maximum. Thus the set of efficient policies is equivalent to the set of inflation targets with gradual adjustment. 
The final set of results concerns nominal-income targets. Many economists advocate such a policy, including McCallum (1993, 1995), Hall and Mankiw (1994), and Feldstein and Stock (1994). My model yields strongly negative results about income targeting. This policy is not merely inefficient, it is disastrous, because it causes both output and inflation to follow nonstationary processes. That is, the variances of output and inflation are infinite. This result holds regardless of whether policy targets the level of nominal income or its growth rate. Stability in either of these variables masks instability in output and inflation. Shocks set off oscillations in output and inflation that never die out.

My results are related to those of the papers with similar models, especially Svensson (1996a). My analysis of inflation targets overlaps with Svensson's, but we focus on different issues. My results are surprisingly different from those of Taylor (1994) and Hall and Mankiw (1994): subtle differences in the models prove important. Finally, my results about income targets are related to numerical simulations in Taylor (1985). These connections will be made clear as I proceed.

The rest of the paper contains five sections. Section II presents the model. Sections III-V present the three sets of results. Section VI concludes.

\section{THE MODEL}

\section{A. Assumptions}

The economy is described by two equations:

$$
\begin{array}{ll}
\text { (1) } y=-\beta r_{-1}+\lambda y_{-1}+\epsilon, & \beta>0,0 \leq \lambda \leq 1 ; \\
\text { (2) } \pi=\pi_{-1}+\alpha y_{-1}+\eta, & \alpha>0,
\end{array}
$$

where $y$ is the gap between output and potential output, $r$ is the difference between the real 
interest rate and its equilibrium level, $\pi$ is the difference between inflation and its average level, $\epsilon$ and $\eta$ are white-noise shocks, and $\alpha, \beta$, and $\lambda$ are constants. Note that, following Taylor (1994), I take average inflation as given and ask how policies affect fluctuations. I do not consider the choice of average inflation or transitions from one average level to another.

Equation (1) is a dynamic IS equation. Output depends on the lagged interest rate, lagged output, and a demand shock. Equation (2) is an accelerationist Phillips curve. The change in inflation depends on lagged output and an inflation or "supply" shock.

I assume that the monetary authority uses the interest rate as its policy instrument. Thus the interest rate is most realistically interpreted as an overnight rate. Policymakers set the interest rate after observing the current shocks $\epsilon$ and $\eta$. Note I assume that policymakers set the real interest rate. In practice, the interest rates controlled directly by policymakers are nominal rates. However, policymakers can move the real interest rate to their desired level by setting the nominal rate equal to the desired real rate plus inflation. ${ }^{2}$

The model captures several phenomena that are important for policymaking in practice. Both output and inflation are subject to unforecastable shocks. Output movements are persistent, because lagged output enters equation (1). Inflation is inertial: once it rises, it stays high unless output falls. Finally, policy can offset shocks only with a lag. It takes a period for policy to affect output, and a period for output to affect inflation; combining these lags, it takes two periods for policy to affect inflation. This structure captures the stylized fact that policy affects output more quickly than it affects inflation (e.g. McCallum, 1995).

The main virtues of the model are simplicity and realism. An important limitation is that the

${ }^{2}$ It is, of course, a simplification to assume that spending depends directly on the overnight interest rate. Future work might consider an extension in which spending depends on a longer-term interest rate, which is linked to the overnight rate through the term structure. 
model ignores the Lucas critique. I assume that equations (1) and (2) remain unchanged across different policy regimes, and this may be untrue. We must keep this possibility in mind when interpreting the results.

\section{B. Calibration}

In interpreting the model, I will assume that a period is a year. A year is a roughly realistic lag for the effects of policy on output, and two years is about right for inflation (e.g. Christiano et al., 1996). If the model were quarterly, we would clearly need longer lags in the two equations.

In parts of the analysis, it will be useful to have baseline values for the model's parameters. To choose $\alpha$, the Phillips-curve slope, I use the fact that the sacrifice ratio for reducing inflation is $1 / \alpha$. Evidence suggests that a plausible ratio is 2.5 , implying $\alpha=0.4$ (e.g. Ball, 1994b). In the aggregate-spending equation, the coefficient $\lambda$ on lagged output should be large, as output fluctuations are persistent. I assume $\lambda=0.8$, which is close to the lagged-output coefficient when output is regressed on measures of monetary policy (e.g. DeLong and Summers, 1988). Finally, I assume the parameter $\beta$ is 1.0: a one-point rise in the interest rate reduces output by one percent. This is close to the effect in both macroeconometric models and vector autoregressions (Rudebusch, 1995). With $\beta=1.0$, a three-point rise in the interest rate reduces annual growth from $2.5 \%$ to $-0.5 \%$

\section{TAYLOR RULES}

\section{A. Efficient Policies}

What is the optimal policy rule in my model? The optimal rule minimizes a weighted sum of output variance and inflation variance, with the weights determined by policymakers' tastes. One way to derive the optimal rule is to posit a general rule, derive the two variances as 
functions of the rule's parameters, and find the parameters that minimize the objective function. However, it is easier to first derive some restrictions on policy that are required for efficiency. I therefore proceed as follows.

A policy rule is a rule for setting the interest rate $r$. The interest rate affects the economy because it determines expected output in the following period. Specifically, equation (1) implies that expected output is

$$
E\left[y_{+1}\right]=-\beta r+\lambda y,
$$

where I use the assumption that $\epsilon$ is unforecastable. The policymaker can set $\mathrm{Ey}_{+1}$ at any level he chooses by setting the appropriate $r$ given (3) and the current value of $y$. We can therefore view the policymaker's problem as choosing $E y_{+1}$. Given a rule for Ey $y_{+1}$, equation (3) determines the implied rule for $r$.

When the policymaker chooses $\mathrm{Ey}_{+1}$, what variables are relevant? Inspection of (1) and (2) shows there is only one state variable. This variable is expected inflation in the next period, $\mathrm{E} \pi_{+1}$, which equals $\pi+\alpha \mathrm{y}$. While the policymaker chooses $\mathrm{Ey} \mathrm{y}_{+1}$, he takes $\mathrm{E} \pi_{+1}$ as given because he affects inflation only after two periods. The future of the economy is determined by the state variable $\mathrm{E} \pi_{+1}$, the policymaker's rule for $\mathrm{E} y_{+1}$, and future shocks. Thus policymakers set $\mathrm{Ey} \mathrm{y}_{+1}$ as a function of $E \pi_{+1}$. Since the model is linear-quadratic, one can show that the optimal policy is linear. Thus

$$
\text { (4) } \begin{aligned}
E\left[y_{+1}\right] & =-q E\left[\pi_{+1}\right] \\
& =-q(\pi+\alpha y),
\end{aligned}
$$

where $\mathrm{q}$ is a parameter to be determined (which will be positive). Combining this equation with (3) yields the interest-rate rule: 


$$
\text { (5) } \quad r=\left(\frac{\lambda+\alpha q}{\beta}\right) y+\frac{q}{\beta} \pi \text {. }
$$

This equation is a Taylor rule: the interest rate responds positively to output and inflation.

It remains to determine the parameter $\mathrm{q}$. The Appendix derives the optimal $\mathrm{q}$ as a function of the model's parameters and the weights that policymakers put on inflation and output variances. As the weight on inflation variance becomes small, the optimal $\mathrm{q}$ approaches zero. In this case, policymakers minimize the variance of output by setting expected output to zero (see (4)). As the weight on inflation rises, the optimal q rises, and so do the coefficients in (5). Thus when policymakers care more about inflation, they react more strongly to movements in output or inflation. As the relative weight on inflation approaches infinity, $\mathrm{q}$ approaches $1 / \alpha$. This choice of q minimizes the variance of inflation. ${ }^{3}$

These results determine the set of efficient policies -- the policies that are optimal for some tastes. These policies are defined by equation (5) with $q$ ranging from zero to $1 / \alpha$. Efficiency implies two kinds of restrictions on the Taylor rule. First, the coefficients in the rule must lie in certain ranges. Since $q$ lies in $(0,1 / \alpha)$, the output coefficient must lie in $(\lambda / \beta,(\lambda+1) / \beta)$ and the inflation coefficient must lie in $(0,1 / \alpha \beta)$. Second, there is a restriction across the coefficients. If the inflation coefficient is $\mathrm{k}_{\pi}$, the output coefficient must equal $\alpha \mathrm{k}_{\pi}+\lambda / \beta{ }^{4}$

${ }^{3}$ Using dynamic programming, Svensson (1996a) derives the interest-rate rule that minimizes the present value of a weighted sum of output and inflation variances. As the discount factor approaches one, Svensson's solution approaches equation (5) with $q$ as defined in the Appendix.

${ }^{4}$ Taylor's (1994) model is similar to mine, except that the IS equation includes the current rather than lagged interest rate. This difference leads to results that are quite different from mine, and quite unappealing. In Taylor's model, efficiency requires that both coefficients in the interest-rate rule approach infinity. See Ball (1994a). 


\section{B. Is Current Policy Efficient?}

Recent research shows that Taylor rules provide a good fit to actual policy in several countries since the mid-1980s. These countries include the United States (Taylor, 1993a, 1994), the United Kingdom (Stuart, 1996), and Germany and Japan (Davies et al., 1996). Observers such as Krugman (1996) praise Taylor rules for "leaning against the wind" in a sensible way. My model provides formal support for the intuition that a Taylor rule is optimal.

At the same time, my model suggests an unfavorable judgment on the particular Taylor rules used in practice. A striking regularity is that the Taylor rules identified in various countries have coefficients of one half on both output and inflation. The past literature says little about whether these coefficients are optimal, or how one could decide. My model suggests that the coefficients are inefficient. In particular, for my base parameter values, the coefficient on output is too low.

To see this, recall that the base parameter values are $\alpha=0.4, \beta=1.0$, and $\lambda=0.8$. For these parameters, efficiency requires an inflation coefficient in the range $(0,2.5)$ and an output coefficient in the range $(0.8,1.8)$. The actual inflation coefficient is within the efficient range, but the output coefficient is not. In addition, the cross-coefficient restriction implies that, for an inflation coefficient of 0.5 , the output coefficient should be 1.0 , twice its actual value.

Why is a low output coefficient inefficient? Recall that a rule for choosing $r$ is equivalent to a rule for choosing expected output in the next period. In this rule, the coefficient on current output is $-\beta \mathrm{k}_{\mathrm{y}}+\lambda$, where $\mathrm{k}_{\mathrm{y}}$ is the output coefficient in the interest-rate rule. For $\mathrm{k}_{\mathrm{y}}=1 / 2$ and base values of $\beta$ and $\lambda$, this expression is positive. Thus a positive output gap implies a positive expected gap in the next period: the interest rate does not rise enough to eliminate output persistence. This fact is the source of inefficiency. Persistence leads to larger output fluctuations, which generate larger inflation fluctuations through the Phillips curve. Policymakers should raise the output coefficient in the Taylor rule to produce a non-positive effect of $y$ on 
$\mathrm{Ey}_{+1}$.

This conclusion is reasonably robust to variation in parameter values. There is, for example, uncertainty about the parameter $\beta$, the effect of the interest rate on output. But, for the base values of $\alpha$ and $\lambda$, an output coefficient of one half is below the efficient range for any $\beta<1.6$. The coefficient is below the level implied by the cross-coefficient restriction for any $\beta<2.67$. This is a generous bound: $\beta=2.67$ implies that a one-point rise in the interest rate pushes growth from its trend level to below zero.

The conclusion that countries with Taylor rules should respond more aggressively to output fluctuations is strengthened by examining recent history. Consider the United Kingdom, where a Taylor rule fits policy since 1986. From 1986 through 1990, the U.K. experienced large positive output gaps, and CPI inflation rose from $3.4 \%$ to $9.5 \%(\mathrm{OECD}, 1996)$. Then the gaps turned negative through 1995 , and inflation ended up back at $3.4 \%$. This boom-bust cycle appears inefficient. If the U.K.'s Taylor rule had a larger coefficient on output, policy would have been tighter in the late $80 \mathrm{~s}$ and looser in the $90 \mathrm{~s}$. This would have dampened the output fluctuations and the temporary run-up in inflation. The same story fits the United States, although the U.S. boom-bust cycle was smaller. ${ }^{5}$

\section{INFLATION TARGETS}

This section considers policies that attempt to achieve a target level of inflation. This goal

5 The more desirable outcomes in the United States reflect the fact that, while policy generally followed a Taylor rule, it deviated at two important points. In 1986, interest rates were much higher than those implied by the rule; in 1992-93, they were lower. Thus the U.S. leaned more heavily against the 80 s boom and 90 s recession than the Taylor rule dictated. Some observers view these deviations as mistakes or responses to special circumstances (Economist, 1996). My analysis suggests that actual policy was better than the simple Taylor rule. 
implicitly defines a rule for setting the interest rate. Inflation targets are of interest because a number of countries have recently adopted them. What relation do these policies have to the efficient policies derived in the previous section?

\section{A. Strict Inflation Targets}

A strict definition of inflation targeting is that policy minimizes the variance of inflation around its average level. As discussed by Svensson (1996a), this implies that policy sets to zero the expected inflation deviation in two periods:

$$
\text { (6) } E \pi_{+2}=0 \text {. }
$$

Recall that policy cannot affect inflation before two periods because of the lags in the model.

A strict inflation target is an efficient policy by definition. It minimizes the weighted sum of output and inflation variances when the weight on output is zero. The implied interest-rate rule is the efficient Taylor rule (5) with $\mathrm{q}$ at its upper bound of $1 / \alpha$. For my base parameter values, this implies $\mathrm{k}_{\mathrm{y}}=1.8$ and $\mathrm{k}_{\pi}=2.5$.

While a strict inflation target is efficient, it is optimal only for extreme tastes. If policymakers care about both output and inflation, they should move interest rates less aggressively. It is not clear whether a strict inflation target would improve on current Taylor rules with coefficients of one half. For base parameter values, one can show that the inflation target would reduce the variance of inflation but raise the variance of output.

\section{B. Inflation Targets with Gradual Adjustment}

Inflation targeting can be made more attractive by defining it more broadly. We can see this by rewriting the condition from Section III defining an efficient Taylor rule. Note first that the Phillips curve (2) implies an expression for expected inflation in two periods: 
According to equation (4), an efficient policy is defined by setting $E y_{+1}$ equal to $-q E \pi_{+1}$. Substituting this condition into (7) yields

$$
E \pi_{+2}=(1-\alpha q) E \pi_{+1} .
$$

One can define the set of efficient policies by equation (8) with q ranging from zero to $1 / \alpha$.

Equation (8) is a generalization of a strict inflation target, equation (6). Instead of setting $E \pi_{+2}$ equal to zero, the rule sets it equal to a fraction of $E \pi_{+1}$. Given the range for $q$, this fraction can range from zero to one. Thus equation (8) is a partial-adjustment variation on an inflation target. Given expected inflation in one period, which policymakers take as given, policy moves expected inflation partway to its long-run target in the following period. ${ }^{6}$

It makes sense that a partial-adjustment rule is the optimal policy. Policymakers want to return inflation to its target, but they face a quadratic cost of changing inflation: a change in inflation requires a deviation of output from potential, and the square of this deviation enters policymakers' loss functions. Recall that policymakers who put a large weight on stabilizing output choose a small value of the parameter q. In equation (8), this means they adjust inflation slowly toward its target. Slow adjustment raises the variance of inflation but reduces the variance of output.

If we define inflation targets to allow partial adjustment, then we have a strong result: the class of efficient policies is equivalent to the class of inflation targets. Thus there exists an inflation target that dominates the inefficient Taylor rules used in practice. And any policymaker

\footnotetext{
${ }^{6}$ Svensson (1996a) also shows the optimality of a partial-adjustment rule for inflation.
} 
should adopt an inflation target, regardless of his tastes. If he cares a lot about stabilizing output, he should choose a slow adjustment speed, but he can still define policy fully by a path for inflation. There is no need to bring output or other variables into the policy rule.

An inflation target with gradual adjustment is probably a good description of policy in some countries. For example, Australia has adopted an inflation target of $2-3 \%$ to be met "on average over the cycle" rather than continuously (Reserve Bank, 1996). This rule appears to allow gradual adjustment after a shock. As discussed by Svensson (1996b), few if any "inflation target" countries have strict targets as defined here. In choosing a short-run path for inflation, policymakers put some weight on the consequences for output.

\section{NOMINAL INCOME TARGETS}

Many economists advocate policies that target nominal GDP. Authors such as Hall and Mankiw (1994) and McCallum (1993, 1995) argue that such policies would produce better outcomes, and particularly more stable output, than inflation targets. In my model, however, nominal-income targets are disastrous. They imply that the variances of output and inflation are infinite.

The literature discusses two kinds of nominal-income targets, growth targets and level targets. Growth targets mean that policy always aims for the same rate of income growth, regardless of past growth. Level targets mean that policy reverses past mistakes to return the income level to a fixed path. I focus here on income-growth targets, which have received the most attention. The Appendix considers level targets and shows they are equally disastrous.

\section{A. Some Unpleasant Algebra}

An income-growth policy minimizes the variance of income growth. Equivalently, it sets the expectation of next period's income growth equal to a fixed target. Note that policy can 
influence income growth in one rather than two periods, because it affects output with a oneperiod lag. In deviations from trend, income growth is the sum of output growth, $y_{+1}-y$, and inflation, $\pi_{+1}$. Thus an income-growth policy is defined by

$$
E\left[y_{+1}-y+\pi_{+1}\right]=0 \text {. }
$$

Equation (9) determines the rule for setting the interest rate. Specifically, substituting (1) and (2) into (9) leads to

$$
\text { (10) } \quad r=\left(\frac{\alpha+\lambda-1}{\beta}\right) y+\frac{1}{\beta} \pi \text {. }
$$

Once again, policy can be expressed as a Taylor rule, although the coefficient on output need not be positive.

The interest-rate rule determines the behavior of output and inflation. Substituting (10) into (1) yields

$$
\text { (11) } y=(1-\alpha) y_{-1}-\pi_{-1}+\epsilon \text {. }
$$

This equation and the Phillips curve, (2), define a vector AR-1 process for output and inflation:

$$
\text { (12) } X=C X_{-1}+E \text {, }
$$

where $\mathrm{X}=[\mathrm{y} \pi]^{\prime}, \mathrm{E}=[\epsilon \eta]^{\prime}$, and $\mathrm{C}$ is a $2 \mathrm{x} 2$ matrix with elements $\mathrm{c}_{11}=(1-\alpha), \mathrm{c}_{12}=-1, \mathrm{c}_{21}=\alpha$, and $\mathrm{c}_{22}=1$.

Finally, the behavior of $y$ and $\pi$ is determined by the eigenvalues of $C$ :

$$
z=\frac{2-\alpha \pm \sqrt{\alpha^{2}-4 \alpha}}{2}
$$

If $\alpha<4$, the eigenvalues are complex and lie on the unit circle. Thus output and inflation follow 
unit-root processes. If $\alpha>4$ (a less realistic case), one eigenvalue is less than -1 , and the processes are explosive. In all cases, y and $\pi$ are non-stationary, so their variances are infinite.

\section{B. Discussion}

This result may appear surprising. A nominal-income rule implies that a particular transformation of inflation and output is stationary (indeed, its variance is minimized). Nonetheless, inflation and output are non-stationary. At a broad level, the explanation is that income growth is an unnatural variable to target, because it is the sum of the inflation level and output growth, and because policy affects these components at different lags. Stability in an unnatural sum can mask instability in its components.

To understand the result, it helps to examine impulse-response functions. Consider the case in which the parameter $\alpha$ equals one, which yields the simplest dynamics. Suppose there is a unit shock to the output equation. Starting with the period of the shock, the path of the vector $[y \pi]$ is [1 0$],\left[\begin{array}{ll}0 & 1\end{array}\right],\left[\begin{array}{ll}-1 & 1\end{array}\right],\left[\begin{array}{ll}-1 & 0\end{array}\right],\left[\begin{array}{ll}0 & -1\end{array}\right],\left[\begin{array}{ll}1 & -1\end{array}\right],\left[\begin{array}{ll}1 & 0\end{array}\right] \ldots$ Both output and inflation oscillate around zero, even though inflation plus the change in output is constant after the first period. The oscillations never die out, explaining why output and inflation follow non-stationary processes.

These oscillations are similar to the "overshooting" in Taylor's (1985) simulations of a nominal-income rule. The problem arises as follows. If inflation rises, policy must cause a recession to bring it back on track. Once inflation returns, it would be optimal to allow output to recover. But recovery to trend would require high output growth; with inflation on target, this would imply above-target growth in nominal income. Thus a nominal-income rule prevents an immediate recovery: it requires that output stay low when inflation returns to target. The continuing recession means that inflation falls below target in the following period. This 
overshooting is the start of the oscillations in inflation and output. ${ }^{7}$

A common argument for income targets over inflation targets is that it is easier to control income (e.g. McCallum, 1995). The reason is that policy affects spending more quickly than it affects inflation. In my model, this point is true but not very relevant to the choice of policy. I assume it takes two periods for policy to move inflation and only one to move spending. And one can show that the variance of income growth under an income target is smaller than the variance of inflation under an inflation target. But the low variance of income growth masks infinite variances of output and inflation, the variables we care about.

\section{CONCLUSION}

The model in this paper has several implications about monetary policy. First, an efficient policy can be expressed as a Taylor rule, but the coefficient on output must be higher than the one in recent U.S. history. Second, an efficient Taylor rule is equivalent to an inflation target with gradual adjustment. Finally, a policy of targeting nominal income is highly inefficient.

While the model is simple, it suggests some general lessons. The result that efficiency implies restrictions on Taylor rules appears robust. Policymakers face a one-dimensional tradeoff between output and inflation variances; thus efficiency restricts the two coefficients in a Taylor rule to a one-dimensional space. Future research could derive efficient Taylor rules in more

${ }^{7}$ In Taylor's simulations, the oscillations die out, so output and inflation are stationary. The reason may be that the coefficient on lagged inflation in Taylor's Phillips curve is less than one.

The simulations in Hall and Mankiw (1994) suggest that income-growth targets are a respectable policy and income-level targets are rather good. These findings are puzzling, because Hall and Mankiw's model is similar to mine. The explanation may be that Hall and Mankiw evaluate their rules by comparing them to U.S. policy in the 1970s and 80s. Policy was sufficiently unstable during that period that almost any rule would have been an improvement. 
complicated models.

The negative result about nominal-income targets is also of general importance. Economists such as McCallum and Hall and Mankiw argue that a policy rule should be "robust": it should produce good outcomes across a range of macroeconomic models. They advocate income targeting on the grounds that it is a robust policy. My results are a counter-example to this claim. In one reasonable model, income targets are disastrous.

In my model, the non-trivial choice facing policymakers -- the one not determined by efficiency alone -- is the speed of adjustment to an inflation target. Equivalently, the key choice is the parameter $\mathrm{q}$ in the Taylor rule. If one makes a judgment about the weights on output and inflation variances, one can derive the optimal speed of adjustment. Here, however, I doubt the results would be robust. There are at least two relevant issues that the model ignores.

First, the output-inflation tradeoff may vary with the speed of adjustment. My model assumes that the sacrifice ratio for reducing inflation is fixed at $1 / \alpha$. But the empirical results in Ball (1994b) suggest that the sacrifice ratio is smaller if disinflation is quick. This effect increases the optimal speed of adjustment to an inflation target. If the effect is large enough, output variance is minimized by immediate adjustment, i.e. a strict inflation target, and this policy dominates all others.

Second, the model ignores the problem of parameter uncertainty. Real-world policymakers do not know what potential output is, how much an interest-rate change will change spending, and so on. Economists often argue that such uncertainty should make countercyclical policy less aggressive. In the present context, this means a lower value of the parameter $\mathrm{q}$ or slower adjustment to an inflation target. This idea could be explored by adding parameter uncertainty to the model. 


\section{APPENDIX}

\section{A. Derivation of the Optimal Taylor Rule}

Here I derive the optimal value of the parameter $q$ in equation (5). This completes the solution for the optimal interest-rate rule.

Substituting (5) into (1) yields

$$
y=-\alpha q y_{-1}-q \pi_{-1}+\epsilon .
$$

This equation and (2) define a vector AR-1 process for output and inflation:

$$
X=B X_{-1}+E,
$$

where $\mathrm{X}=[\mathrm{y} \pi]^{\prime}, \mathrm{E}=[\epsilon \eta]^{\prime}$, and $\mathrm{B}$ is a $2 \times 2$ matrix with elements $\mathrm{b}_{11}=-\alpha \mathrm{q}, \mathrm{b}_{12}=-\mathrm{q}, \mathrm{b}_{21}=\alpha$, and $b_{22}=1$. The variance-covariance matrix of $X$, denoted $V$, is given in vector form by

$$
\operatorname{vec}(V)=[I-(B \otimes B)]^{-1} \operatorname{vec}(\Omega),
$$

where $\Omega$ is the variance-covariance matrix of E. (See Hendry, 1995, p. 112). After taking the inverse in (A3), one can find the variances of $y$ and $\pi$ :

$$
\left[\begin{array}{ll}
V_{y} & V_{\pi}
\end{array}\right]^{\prime}=D\left[\begin{array}{lll}
\sigma_{\epsilon}^{2} & \sigma_{\eta}^{2}
\end{array}\right]^{\prime}
$$

where $\sigma_{\epsilon}^{2}$ and $\sigma_{\eta}^{2}$ are the variances of $\epsilon$ and $\eta$ and $D$ is a $2 \times 2$ matrix with elements $d_{11}=2 /(2-\alpha q)$, $d_{12}=q /\left(2 \alpha-\alpha^{2} q\right), d_{21}=\alpha /\left(2 q-\alpha q^{2}\right)$, and $d_{22}=\left(1+2 \alpha q-\alpha^{2} q^{2}\right) /\left(2 \alpha q-\alpha^{2} q^{2}\right)$.

The optimal value of $\mathrm{q}$ is the one that minimizes $\mathrm{V}_{\mathrm{y}}+\mu \mathrm{V}_{\mathrm{x}}$, where $\mu$ is a weight chosen by policymakers. The solution to this minimization problem is

$$
q=\frac{-\mu \alpha+\sqrt{\mu^{2} \alpha^{2}+4 \mu}}{2}
$$


As claimed in the text, $\mathrm{q}$ approaches zero as $\mu$ approaches zero, increases with $\mu$, and approaches $1 / \alpha$ as $\mu$ approaches infinity.

\section{B. Income Level Targets}

Section $V$ shows that a target for nominal-income growth leads to non-stationary processes for output and inflation. Here I show that a target for the level of nominal income does the same.

Under income-level targeting, policymakers minimize the variance of income around a fixed path. Equivalently, they set the expectation of next period's income equal to a target:

$$
E\left[y_{+1}+p_{+1}\right]=0 \text {, }
$$

where $\mathrm{p}$ is the deviation of the log price level from its trend. Using the fact that $\mathrm{p}_{+1}=\mathrm{p}+\pi_{+1}$, and substituting (1) and (2) into (A6), the implied interest-rate rule is

$$
r=\frac{(\alpha+\lambda) y+\pi+p}{\beta} .
$$

Substituting (A7) into (1) yields

$$
y=-\alpha y_{-1}-\pi_{-1}-p_{-1}+\epsilon .
$$

Using (2) and the fact that $\mathrm{p}=\mathrm{p}_{.1}+\pi$, we have

(A9) $\quad p=\alpha y_{-1}+\pi_{-1}+p_{-1}+\eta$.

Equations (A8), (A9), and (2) define a vector AR-1 process for $\mathrm{y}, \pi$, and $\mathrm{p}$ :

$$
\text { (A10) } Z=H Z_{-1}+M \text {, }
$$

where $\mathrm{Z}=[\mathrm{y} \pi \mathrm{p}]^{\prime}, \mathrm{M}=[\epsilon \eta \eta]$, and $\mathrm{H}$ is a $3 \times 3$ matrix with elements given by the coefficients 
in (A8), (A9), and (2).

The matrix $\mathrm{H}$ has three eigenvalues. One eigenvalue is zero, and the other two are given by equation (13). For $\alpha<4$, the non-zero eigenvalues are complex and lie on the unit circle; for $\alpha>4$, they are real and one is less than -1 . In all cases, $y, \pi$, and $\mathrm{p}$ follow non-stationary processes. 


\section{REFERENCES}

Ball, Laurence, "Discussion," in Jeffrey C. Fuhrer (ed.), Goals, Guidelines, and Constraints Facing Monetary Policymakers Federal Reserve Bank of Boston, 1994a.

, "What Determines the Sacrifice Ratio?," in N. Gregory Mankiw (ed.), Monetary Policy, University of Chicago Press, 1994b.

Bean, Charles R., "Targeting Nominal Income: An Appraisal," Economic Journal 93 (1983), 806-19.

Bryant, Ralph, Peter Hooper, and Catherine Mann (eds.), Evaluating Policy Regimes: New Research in Empirical Macroeconomics, The Brookings Institution, 1993.

Christiano, Lawrence J., Martin Eichenbaum, and Charles Evans, "The Effects of Monetary Policy Shocks: Evidence from the Flow of Funds," Review of Economics and Statistics 78 (February 1996), 16-34.

Cukierman, Alex, "Towards a Systematic Comparison Between Inflation Targets and Monetary Targets," in Leonardo Leiderman and Lars E.O. Svensson (eds.), Inflation Targets, Centre for Economic Policy Research, 1995.

Davies, Gavyn, Martin Brookes, and Stuart Culverhouse, Goldman Sachs report, 1996.

DeLong, J. Bradford, and Lawrence H. Summers, "How Does Macroeconomic Policy Affect Output?," Brookings Papers on Economic Activity 1988:2, 433-80.

The Economist, "Economics Focus," August 10 1996, p. 60.

Feldstein, Martin, and James H. Stock, "The Use of a Monetary Aggregate to Target Nominal GDP," in N. Gregory Mankiw (ed.), Monetary Policy, University of Chicago Press, 1994.

Frankel, Jeffrey, with Menzie Chinn, "The Stabilizing Properties of a Nominal GNP Rule," Journal of Money, Credit, and Banking 27 (1995), 318-34.

Hall, Robert E., and N. Gregory Mankiw, "Nominal Income Targeting," in N. Gregory Mankiw (ed.), Monetary Policy, University of Chicago Press, 1994.

Hansen, Eric, "Price Level versus Inflation Targets in an Open Economy with Overlapping Wage Contracts," Reserve Bank of New Zealand, May 1996. 
Henderson, Dale W. and Warwick J. McKibbin, "A Comparison of Some Basic Monetary Policy Regimes for Open Economies: Implications of Different Degrees of Instrument Adjustment and Wage Persistence," Carnegie-Rochester Conference Series on Public Policy 39 (December 1993), 221-317.

Hendry, David F., Dynamic Econometrics, Oxford University Press, 1995.

Krugman, Paul, "Stable Prices and Fast Growth: Just Say No," The Economist, August 31 1996, 15-18.

Matheny, Kenneth J., "Output Targeting and an Argument for Stabilization Policies," Purdue University, 1996.

McCallum, Bennett T., "Specification and Analysis of a Monetary Policy Rule for Japan," Bank of Japan Monetary and Economic Studies 11 (1993), 1-45.

, "New Zealand's Monetary Policy Arrangements: Some Critical Issues," Reserve Bank of New Zealand Discussion Paper G95/4, June 1995.

Organization for Economic Cooperation and Development, Economic Outlook 59 (June 1996).

Reserve Bank of Australia, "Statement on the Conduct of Monetary Policy," Bulletin, September 1996.

Rudebusch, Glenn, "What Are the Lags in Monetary Policy?," FRBSF Weekly Letter, 9505 (February 3 1995).

Stuart, Alison, "Simple Monetary Policy Rules," Bank of England Quarterly Bulletin 36 (August 1996), 281-287.

Svensson, Lars E.O., "Inflation Forecast Targeting: Implementing and Monitoring Inflation Targets," Stockholm University, 1996a.

, "Optimal Inflation Targets, 'Conservative' Central Banks, and Linear Inflation Contracts," Stockholm University, $1996 \mathrm{~b}$.

Taylor, John B., "What Would Nominal GNP Targetting Do to the Business Cycle?," Carnegie-Rochester Conference Series on Public Policy 22 (Spring 1985), 61-84.

, "Discretion Versus Policy Rules in Practice," Carnegie-Rochester Conference Series on Public Policy 39 (December 1993a), 195-214.

, Macroeconomic Policy in the World Economy: From Econometric Design to Practical Operation, W.W. Norton, 1993 b.

, "The Inflation / Output Variability Trade-off Revisited," in Jeffrey C. Fuhrer 
(ed.), Goals, Guidelines, and Constraints Facing Monetary Policymakers, Federal Reserve Bank of Boston, 1994.

West, Kenneth D., "Targeting Nominal Income: A Note," Economic Journal 96 (1986), 1077-83. 